\title{
Immunobiology of liver xenotransplantation
}

\author{
Burcin Ekser ${ }^{1,2,3}$, Christopher Burlak ${ }^{2}$, Joshua P Waldman ${ }^{4}$, Andrew J Lutz ${ }^{2}$, Leela L \\ Paris $^{2}$, Massimiliano Veroux ${ }^{3}$, Simon C Robson ${ }^{5}$, Michael A Rees ${ }^{4}$, David Ayares ${ }^{6}$, Bruno \\ Gridelli $^{1,7}$, A Joseph Tector ${ }^{2}$, and David KC Cooper ${ }^{*}, 1$ \\ ${ }^{1}$ Thomas E. Starzl Transplantation Institute, University of Pittsburgh Medical Center, Pittsburgh, \\ PA, USA \\ ${ }^{2}$ Department of Surgery, Transplant Institute, Indiana University School of Medicine, Indiana \\ University Health, Indianapolis, IN, USA \\ ${ }^{3}$ Department of Surgery, Transplantation and Advanced Technologies, Vascular Surgery and \\ Organ Transplant Unit, University Hospital of Catania, Catania, Italy \\ ${ }^{4}$ Department of Urology, University of Toledo Health Sciences Campus, Toledo, OH, USA \\ ${ }^{5}$ Liver Center, Department of Medicine, Beth Israel Deaconess Medical Center, Harvard Medical \\ School, Boston, MA, USA \\ ${ }^{6}$ Revivicor, Inc., Blacksburg, VA, USA \\ ${ }^{7}$ Mediterranean Institute for Transplantation and Advanced Specialized Therapies (ISMETT), \\ Palermo, Italy
}

\begin{abstract}
Pigs are currently the preferred species for future organ xenotransplantation. With advances in the development of genetically modified pigs, clinical xenotransplantation is becoming closer to reality. In preclinical studies (pig-to-nonhuman primate), the xenotransplantation of livers from pigs transgenic for human CD55 or from a1,3-galactosyltransferase gene-knockout pigs+/transgenic for human CD46, is associated with survival of approximately 7-9 days. Although hepatic function, including coagulation, has proved to be satisfactory, the immediate development of thrombocytopenia is very limiting for pig liver xenotransplantation even as a 'bridge' to allotransplantation. Current studies are directed to understand the immunobiology of platelet activation, aggregation and phagocytosis, in particular the interaction between platelets and liver sinusoidal endothelial cells, hepatocytes and Kupffer cells, toward identifying interventions that may enable clinical application.
\end{abstract}

\section{Keywords}

a1,3-galactosyltransferase gene-knockout; hCD46; liver; liver failure; nonhuman primate; pig; xenotransplantation

The most effective clinical therapy for end-stage organ failure remains that of transplantation. However, the shortage of organs from deceased as well as living donors,

\footnotetext{
(C) 2012 Expert Reviews Ltd

*Author for correspondence: Tel.: +1 4123836961 Fax: +1 4126241172 cooperdk@ upmc.edu.

Financial \& competing interests disclosure: The authors have no other relevant affiliations or financial involvement with any organization or entity with a financial interest in or financial conflict with the subject matter or materials discussed in the manuscript apart from those disclosed.
} 
especially for certain organs, such as the liver and heart, limits this option for many patients. In the USA, there are approximately 110,000 patients currently waiting for an organ (April 2012) [201]. Although dialysis and ventricular assist devices are options for chronic kidney and heart failure, respectively, therapeutic options are limited for those who wait for a donor liver. In April 2012, the liver transplantation waiting list was close to 17,000 patients [1].

Liver transplantation is mainly performed in patients with chronic end-stage liver failure. However, liver transplantation can be a lifesaving option in patients with acute liver failure (ALF) when conventional medical therapy fails [1]. United States National Organ Sharing median waiting time for the most urgent listing for ALF patients (liver status 1) is 6 days [2]. Some patients with ALF need to be transplanted within 24-36 $\mathrm{h}$ before rapid clinical deterioration renders them unsuitable candidates for transplantation [3]. Between 1995 and 2011, 38,760 patients were removed from the liver waiting list because they either died while awaiting a suitable organ or became too sick for transplantation [1].

Xenotransplantation (i.e., cross-species transplantation, e.g., pig-to-human) may resolve the shortage of suitable donor organs [4]. Pigs are considered to be the preferred species for clinical xenotransplantation due to several factors, which include: similarities in pig organ size and physiology to humans; their ability to breed rapidly; their ability to be genetically engineered; low risk of cross-species transmission of infectious microorganisms to humans; and that their use for this purpose would be ethically acceptable to the majority of the population [4].

As complicated as organ allotransplantation is with its immunological obstacles, such as hyperacute rejection, acute cellular rejection and chronic rejection, xenotransplantation is even more complex with greater immunological barriers as well as cross-species incompatibilities, such as those associated with coagulation factors.

This review will discuss the immunobiological obstacles to successful liver xenotransplantation, largely through reference to the pig-to-non human primate model and potential solutions to these challenges.

\section{Major immunological barriers to organ xenotransplantation}

Hyperacute rejection (HAR) is the first barrier. It occurs within minutes to hours due to the binding of natural (preformed) antibodies to antigens expressed on the pig vascular endothelium, which initiates activation of the complement cascade (Figure 1) [5-7]. HAR is histologically observed as diffuse interstitial hemorrhage, edema and thrombosis of small vessels. The main antigen on pig vascular endothelium targeted by preformed antibodies has a terminal carbohydrate epitope, Gala1, 3Gal (Gal), which is added by the a1,3galactosyltransferase enzyme [8,9] (reviewed in [10]).

The generation of a1,3-galactosyltransferase gene-knockout (GTKO) pigs has largely overcome the barrier of HAR and given way to a delayed form of antibody-mediated rejection in which the injury develops within days to weeks - termed acute humoral xenograft rejection (AHXR) (also known as delayed xenograft rejection or acute vascular rejection) [7,11,12]. The effect of AHXR cannot be determined per se because baboons receiving GTKO pig liver transplants succumb to bleeding caused by thrombocytopenia within the first $7-10$ days $[13,14]$. Strategies to overcome the acute thrombocytopenia (discussed below), by prolonging graft survival may allow further antibody-mediated graft damage due to preformed or elicited anti-nonGal antibodies (Figure 1) [15-17].

Several studies have been attempted to identify other non-Gal xenoantigens. Byrne et al. and Burlak et al. have independently published several potential xenoantigens which may be involved in cardiac or liver xenograft rejection, respectively [18-20]. In spite of the 
abundance of human antibodies directed to $\mathrm{N}$-glycolylneuraminic acid (anti-HanganutziuDeicher antibodies), and other anti-nonGal antibodies in the blood, if graft and/or recipient survival is short due to the thrombocytopenia, these antibodies may have little impact on liver xenotransplantation.

Pig endothelial cell activation, which is mediated by antibody binding and complement activation, and cellular components of the innate immune system, such as neutrophils, macrophages and natural killer cells, probably all play a role (Figure 1) [21].

Acute cellular rejection, hitherto rarely described in organ xenotransplantation, can probably occur when HAR and AHXR are prevented (Figure 1). However, potent pharmacological agents can largely prevent $\mathrm{T}$ - and B-cell infiltration of the graft and T-cell activation, as well as a T-cell-dependent elicited antibody response [6].

\section{Specific obstacles to liver xenotransplantation}

The only reported experience of clinical pig liver xenotransplantation was in 1995 by Makowa et al. [22] using a wild-type (WT) pig liver in a 26-year-old patient with ALF and grade III encephalopathy. After the depletion of natural (preformed) anti-pig antibodies by plasmapheresis and ex vivo perfusion of the donor pig kidneys, the pig liver was transplanted heterotopically in an effort to bridge the patient to allotransplantation. Although there was evidence of initial function of the pig liver by bile production and reduction in the circulating levels of lactic acid and liver transaminases, the level of anti-pig antibodies rapidly increased resulting in antibody-mediated rejection within a short period of time. A liver biopsy obtained $3 \mathrm{~h}$ post-transplantation showed deposition of antibody and complement components, and endothelial swelling, suggesting early graft rejection. At $34 \mathrm{~h}$ after transplantation, the pig liver showed thrombosis and ischemic necrosis, by which time the patient had developed brain death [22].

In the preclinical setting of WT pig-to-nonhuman primate liver xenotransplantation, the outcomes have been similar [13,22-28]. Early experience in the year 1968 by Calne et al. [23] reported thrombocytopenia and uncontrollable hemorrhage. In the year 1994, Powelson et al. [25] tried to adsorb anti-aGal antibodies using a Gal immunoaffinity column or pig organ, but the survival of the subsequent WT liver graft did not extend $>3$ days. Several groups have documented HAR of WT pig livers, with immunohistopathology showing IgG, IgM, C3, C4d and C5b-9 deposition [26,27,29]. The development of HAR in the WT pig liver was documented by serial wedge biopsies [29] that indicated the development of acute hemorrhagic coagulative necrosis, possible infarction and fibrin thrombi. There was also evidence of antibody and complement deposition in the graft, associated with severe thrombocytopenia.

With the availability of genetically engineered pigs, Ramírez et al. orthotopically transplanted livers from pigs transgenic for human CD55 (decay accelerating factor; a complement regulatory protein) [27]. Two baboon recipients survived 4 and 8 days, respectively. In both cases, there was no sign of HAR, but thrombocytopenia began developing on post-transplant day 1 , with significant reductions in fibrinogen and elevations of D-dimer indicating consumptive coagulopathy [27]. The same group reported five liver xenotransplants from pigs transgenic for human CD55, CD59 and H-transferase; but the survival of the baboons was limited to <24 $\mathrm{h}[30]$.

In 2003, GTKO pigs that did not express Gal antigens, became available [31]. The first preclinical trials using kidneys [32] and hearts [33,34] from GTKO pigs were reported in 2005 , with extended survival of nonhuman primates for almost 3 months for a kidney xenograft and 6 months for a heart xenograft. Despite the absence of HAR and of classical 
AHXR, survival of the grafts was limited by either the development of a thrombotic microangiopathy and/or consumptive coagulopathy [32-36].

The Pittsburgh group recently reported their experience in baboons with liver xenotransplantation using GTKO pigs or GTKO pigs transgenic for human (h) CD46 (GTKO.hCD46) and a clinically applicable immunosuppressive regimen (Table 1) $[13,28,29,37]$. Recipient survival was limited to 7 days due to the rapid development of severe thrombocytopenia, resulting in spontaneous hemorrhages in various native organs and tissues, and in the liver xenograft $[13,29]$. Thrombocytopenia developed within $1 \mathrm{~h}$ posttransplantation (in previous experiments reported by Tector et al. in a model of dog-to-pig liver xenotransplantation, thrombocytopenia occurred within 15 min post-transplantation) $[38,39]$. Despite immediate thrombocytopenia, liver function was documented near-normal to normal (as assessed by liver enzymes, coagulation factors, coagulation assays and production of porcine-specific proteins) [37].

There was no HAR (as documented in 2-h liver biopsies) and no definitive humoral and cellular rejection (as documented at the time of euthanasia or death, at 4-7 days posttransplant) [29]. Immunohistochemistry showed minimal deposition of IgM, and almost an absence of deposition of IgG, C3, C4d or C5b-9, and cellular infiltration ( $\mathrm{T}$ and B cells). Studies with confocal and electron microscopy confirmed platelet aggregation, plateletfibrin thrombi and monocyte/macrophage margination, largely in the liver sinusoids [29].

Recently, the Boston group reported GTKO pig liver xenotransplantation in baboons with an intensive immunosuppressive regimen (Table 1) [14]. Their two cases survived 6 and 9 days, respectively, being the longest in the literature to date. In the 9-day surviving baboon, loss of platelets was ameliorated by the administration of aminocaproic acid, a derivative and analogue of the amino acid, lysine, which makes it an effective inhibitor of lysine binding site of plasmin, thereby blocking fibrinolysis. Although thrombocytopenia was marginal (platelet counts remained between 40 and $50,000 / \mathrm{mm}^{3}$ ) the baboon also suffered severe blood loss. The 9-day surviving baboon further developed definite sepsis, which was also suspected in the 6-day surviving baboon [14].

\section{Where do platelets go? Platelet activation, aggregation \& phagocytosis in liver xenotransplantation}

It is well known that platelets are important factors in survival of vascularized organ allotransplants [40], influencing interactions of monocytes/macrophages and $\mathrm{T}$ cells with endothelial cells (ECs) through secretion of multiple chemokines and expression of ligands for receptors, such as MIP-1a, RANTES, MCP-3 and PF4. After macrophages and T cells localize to a vessel with activated platelets, cellular interactions are promulgated through receptor-ligand interactions. Activated platelets express P-selectin and CD40L (CD154). Macrophages express PSGL-1 and CD40. In addition to CD40, MAC-1 on macrophages can interact with CD154 on both platelets and T cells [40]. Although receptor- ligand interactions will not be discussed in depth, we believe that the expression of CD40L on platelets should be emphasized, especially in the setting of xenotransplantation, since several groups have included anti-CD154 monoclonal antibody (mAb) in their immunosuppressive regimens.

In order to understand the kinetics of platelet activation, aggregation and phagocytosis in liver xenotransplantation, studies have been carried out in vivo in the pig-to-nonhuman primate model [41,42], ex vivo in pig liver perfusion with human blood [43-46], in a closedcircuit perfusion of a pig liver by a baboon [47] and in vitro with isolated liver sinusoidal ECs (LSECs) and Kupffer cells [48 -51]. 


\section{In vivo studies}

The Pittsburgh group recently studied platelet-white blood cell (WBC) aggregation in recipients of orthotopic liver xenografts from GTKO.hCD46 pigs by daily flow cytometry for 7 days $[13,41]$. The development of profound thrombocytopenia was associated with aggregation of platelets and of platelets with WBC-subtypes, especially with monocytes. Although mean platelet volume remained stable throughout the experiment, platelet count significantly fell within the first hour after the transplant (Figure 2). Post-transplant biopsies at $2 \mathrm{~h}$ demonstrated platelet and fibrin deposition by immunofluorescence and electron microscopy (Figure 3). This group concluded that the early disappearance of platelets from the circulation was in part due to platelet-platelet and platelet-WBC aggregation peripherally, resulting in measurement of falsely low platelet counts. However, the presence of aggregated platelets in the blood and in the liver grafts, and possibly in the native lungs, prevented normal platelet function, resulting in spontaneous hemorrhage [41]. Platelet aggregation was seen in the liver sinusoids together with peripheral blood mononuclear cells (PBMCs) $[13,29,42]$ and fibrin $[29,42]$, as shown by confocal and electron microscopy.

The same group investigated the activation of pig LSECs and circulating baboon platelets and PBMCs [42]. There are two types of EC activation. Type I activation of ECs is mediated by ligands binding to the extracellular domains of $G$ protein-coupled receptors, inducing display of P-selectin and vascular leakiness of plasma proteins [7,52]; this process takes 1020 min. Type II activation of ECs is triggered by stimulation of TNF- $\alpha$ and IL-1, induces more effective leukocyte recruitment by synthesis of adhesion proteins, such as E-selectin and CD106 (vascular cell adhesion molecule-1), and is sustained for 6-24 h after cytokinemediated activation [7,53]. Type I and Type II EC activation are usually believed to be associated with HAR and AHXR, respectively [54]. The activated ECs and the generated thrombin may subsequently activate platelets, leukocytes and other inflammatory cells in the recipient, initiating a vicious cycle.

The Pittsburgh group found that $2 \mathrm{~h}$ after liver xenotransplantation, circulating platelets and PBMCs were already activated and secreted tissue factor (TF) (CD142) [42]. The measurement of platelet and EC microparticles suggested that the microparticles in the plasma originate mainly from activated platelets showing TF (CD142)-positivity. Anti-pig CD31 staining, which could only come from LSECs, suggested minimal pig EC activation throughout the experiment. Moreover, Type I (P-selectin), Type II (E-selectin and vascular cell adhesion molecule-1) EC activation, and TF (CD142), and von Willebrand factor (vWF) expression were tested by sequential immunofluorescent staining of the grafts. Expression of Type I and II EC activation markers and CD142 expression were significantly lower in 2-h biopsies. However, expression of EC activation markers and TF was present at the time of death or euthanasia (days 4-7) (and in a WT graft that underwent HAR [2-5 h]). vWF expression was negative in pretransplant biopsies, but became positive in the 2-h biopsies, which could indicate that pig vWF activates baboon platelets [42], as previously noted by Schulte am Esch et al. [55,56].

The Pittsburgh study [29] supported Tector et al.'s observation of possible platelet activation and consequent sequestration in the native lungs $[38,39]$. Platelet staining was positive only when there had been massive interstitial bleeding in native organs (heart, kidney, small bowel and lymph nodes), except in the native lungs where it was positive even in the absence of bleeding [29].

\section{Ex vivo studies}

The Indianapolis group used WT pig livers with human blood in an ex vivo perfusion model [43]. By performing serial biopsies (preperfusion and 15,30, 45, 90 and 120 min during 
perfusion), they showed, for the first time, that pig LSECs and hepatocytes phagocytized human platelets, beginning within 15 min (Figure 4) [43].

Using GTKO.hCD46 pig livers in an ex vivo perfusion circuit and a heparinized baboon, the Maryland group explored whether the development of thrombocytopenia could be delayed [47]. They targeted the glycoprotein Ib-vWF axis by administering anti-GPIb antibody to the baboon, and depleting vWF from the donor pig using desmopressin (on days -1 and 0 preperfusion). Two doses of anti-GPIb antibody (at the time of perfusion and at $30 \mathrm{~min}$ ) significantly delayed the development of thrombocytopenia for up to $3 \mathrm{~h} \mathrm{[47].} \mathrm{Though}$ several questions remain, such as: how frequently, and for how long do we need to administer anti-GPIb antibody? What would be the effect of prolonged anti-GPIb antibody on the coagulation pathways? And will the anti-GPIb antibody have any detrimental effect in vivo? their pilot study [47] suggested the possibility that the GPIb-vWF axis could be targeted in the donor pig by genetic engineering.

Of relevance to these studies is the effect of the transplantation of lungs from vWF-deficient pigs [57]. Cantu et al. demonstrated that deficiency of porcine vWF, which activates human and primate platelets, could extend lung xenograft survival [57]. The Maryland group applied this approach to liver xenografts, with some encouraging data [47].

As an alternative to liver transplantation, other groups have suggested the use of a pig liver for extracorporeal perfusion to 'bridge' a patient to allotransplantation [58]. Rees et al. reported that the platelet count fell to $<30,000 / \mathrm{mm}^{3}$ within $15 \mathrm{~min}$ of initiating ex vivo pig liver perfusion with human blood and also identified loss of human erythrocytes as a major problem [44,45]. Using an ex vivo model of perfusion wherein WT and hCD55 transgenic pig livers were perfused with human blood for up to $72 \mathrm{~h}$, this group showed that pig livers consumed the equivalent of 3 units of human red blood cells (hRBC) [44,45]. This 'graftversus-host' reaction towards human erythrocytes was not caused by the classical pathway of complement lysis, but rather was mediated by phagocytosis by Kupffer cells in the liver in the absence of opsonization $[46,59,60]$.

Burlak et al. showed that porcine Kupffer cell recognition of human erythrocytes was dependant on the expression of the $N$-acetylneuraminic acid form of sialic acid on the surface of the human erythrocyte [61]. In studies investigating porcine Kupffer cell recognition of human erythrocytes in vitro, Burlak et al. was able to show decreased erythrocyte rosetting upon pretreatment of Kupffer cells with $\mathrm{N}$-acetylneuraminic acid. Furthermore, these studies illustrated that the removal of sialic acid from the surface of human erythrocytes completely abrogated Kupffer cell-mediated binding.

Knowing the oligosaccharide on the surface of the $\mathrm{hRBCs}$ responsible for mediating the interaction between porcine macrophages and human erythrocytes, Brock et al. carried out studies aimed at identifying the lectin on the surface of the porcine macrophage responsible for mediating this interaction [62]. Sialoadhesin (CD169) expressed on the surface of porcine macrophages was identified as being responsible for binding of $\mathrm{N}$-acetylneuraminic acid on the surface of the human erythrocyte [62]. Additionally, this in vitro study showed that pretreatment of porcine macrophages with antiporcine CD169mAb could reduce human erythrocyte binding to levels equivalent to that of allogeneic erythrocyte binding.

Recently, Waldman et al. performed a series of ex vivo studies wherein isolated human erythrocytes were perfused through a WT pig liver in the presence of an antiporcine $\mathrm{CD} 169 \mathrm{mAb}$ [63]. In this study, anti-pig CD169mAb was administered over a 72-h perfusion period during which time the volume of circulating erythrocytes (hematocrit) was monitored. The presence of the anti-pig CD169mAb reduced human erythrocyte destruction 
when compared with treatment with an isotype mAb. Additionally, improved liver function was observed [63].

The above studies illustrate the involvement of the porcine CD169 receptor interacting with the ligand, $N$-acetylneuraminic acid, in mediating the anti-human erythrocyte response seen when human blood is perfused through a porcine liver. Furthermore, the ex vivo studies performed by Waldman et al. suggest that other potential receptors are involved [63]. Future studies aimed at better understanding the mechanism of human erythrocyte clearance by the porcine liver may benefit from the generation of CD169-deficient pigs.

\section{In vitro studies}

The liver is the major site of synthesis of complement proteins, except for C1q, factor D, properdin and C7 [64]. After pig liver xenotransplantation, the graft will produce pig complement proteins [13,27]. Pig complement will not be damaging to the liver graft (Figure 5), especially if GTKO pigs expressing hCD46 or another human complement regulatory protein are used as the source of the livers. The Pittsburgh group demonstrated that pig complement will be less harmful than human complement to the transplanted pig liver and that total complement activity remains stable or increased after pig liver xenotransplantation $[13,65]$. Moreover, in vitro studies by the same group showed significantly less complement- and antibody-mediated lysis of PBMCs from GTKO.hCD46 pigs (Figure 5) [66]. Therefore, they concluded that livers from GTKO.hCD46 pigs are likely to have an immunologic advantage over other porcine source livers after transplantation into humans [65].

Having demonstrated platelet phagocytosis by pig LSECs, Kupffer cells and hepatocytes in the ex vivo perfusion model, the Indianapolis group investigated receptor/ligand interactions which induce thrombocytopenia [49,50]. They focused on the role of asialoglycoprotein receptor-1 (ASGR1), which is involved in the clearance of platelets [67]. Incubation of isolated pig LSECs from WT and GTKO.hCD55 pig livers with fluorescently labeled human platelets showed that ASGR1 co-localized with platelet phagocytosis [49]. The inhibition of platelet binding and phagocytosis (using asialofetuin and ASGR1-specific antibodies) was dose-dependent. As a second step, they transfected WT and GTKO.hCD55 pig LSECs with antisense RNA of ASGR1 to knock down ASGR1 expression. Isolated proteins from transfected LSECs showed 80 and $87 \%$ of ASGR1 siRNA expression in WT and GTKO.hCD55 pig LSECs, respectively. ASGR1-knock down in LSECs resulted in 21 and $31 \%$ less platelet phagocytosis in vitro by WT and GTKO.hCD55 pig LSECs, respectively [49].

Kupffer cells are liver macrophages and are involved in platelet phagocytosis. CD11b/CD18 (MAC-1) is a well-known receptor pair on macrophages. The Indianapolis group recently investigated the role of CD11b/CD18 on porcine Kupffer cells for human platelet phagocytosis, using isolated Kupffer cells from WT and GTKO.hCD55 pig livers [50]. CD18 co-localized with platelets when phagocytosis occurred. Anti-CD18 antibody inhibited human platelet phagocytosis by pig Kupffer cells by $43-73 \%$ in WT pigs, and by $18-55 \%$ in GTKO.hCD55 pigs. In order to knockdown CD18 on Kupffer cells, they transfected pig Kupffer cells with CD18 antisense RNA, and isolated proteins which showed 24 and 11\% decrease in CD18 receptor expression in WT and GTKO.hCD55 Kupffer cells, respectively. Having obtained limited knockdown of CD18 in Kupffer cells, human platelet binding and phagocytosis was reduced by 32 and 14\% in WT and GTKO.hCD55 pig Kupffer cells, respectively [50].

The Boston group has also recently investigated integrin-dependent baboon platelet activation and phagocytosis in vitro by isolated WT and GTKO pig hepatocytes and LSECs 
[51], also implicating the ASGR1 [вовsоn sc, pers. сомм.]. With crystal field stabilisation energieslabeled platelets, they showed that when pig platelets were added to pig LSECs, there was no phagocytosis. However, when baboon platelets were added to pig LSECs, there was strong phagocytosis of the platelets. Although pig LSECs and aortic ECs phagocytized baboon platelets (LSECs significantly more than pig aortic ECs), pig hepatocytes did not phagocytize baboon platelets in vitro [Rовson sc, РERs. сомм.] [51]. Eptifibatide and anti-MAC-1 antibody (anti- $\alpha M \beta 2$ integrin antibody), which targeted the integrin receptor on the LSECs, significantly reduced platelet phagocytosis [51].

The Indianapolis group recently investigated the differences between human and porcine platelets that may influence phagocytosis by pig LSECs [48]. Human platelets have four times more exposed galactose $\beta 1-4 N$-acetyl glucosamine (Gal $\beta$ ) and $N$-acetyl glucosamine $\beta 1-4 N$-acetyl glucosamine ( $\beta$ GlcNAc) than porcine platelets. Gal $\beta$ and $\beta$ GlcNAc moieties on pig platelets were not masked by sialic acid. They showed that the removal of sialic acid from human platelets increased binding and phagocytosis by pig LSECs and Kupffer cells [48]. (Various degrees of $O$-linked glycosylation of pig vWF A1 domains also modulate levels of functional interaction with primate platelet receptor GPIb and consequent platelet aggregation responses in vitro) [66].

\section{Potential solutions to cross-species incompatibilities \& thromboregulation}

With the availability of GTKO pigs ${ }^{+/}$transgenic for one or more human complement regulatory proteins (CD55, CD46 and CD59), HAR and AHXR have been significantly ameliorated [68]. However, specific barriers have been identified, such as cross-species thromboregulation and signal (protein) incompatibilities.

\section{Cross-species SIRPa-CD47 interaction}

Liver macrophages (Kupffer cells) and LSECs express signal regulatory protein-a (SIRPa), which enables the cell to identify 'self' from 'non self' and control phagocytosis (Figure 6) [69,70]. SIRPa recognizes a 'self' signal, CD47, which is ubiquitously expressed, including on the surface of erythrocytes and platelets. The correct 'species compatible' SIRPa-CD47 interaction prevents phagocytosis [71,72]. It was known that human SIRPa can bind pig CD47 [73], but is incapable of initiating the signal to inhibit phagocytosis. What remains unknown is if porcine SIRPa can bind human CD47. Paris et al. recently presented data that suggest there is an incompatibility in the initiation of signaling in the porcine SIRPa/human CD47 pathway to inhibit phagocytosis of human platelets by pig cells [70].

Although one could argue that the ideal modification for the liver-source pig would be expression of human SIRPa on pig LSECs and Kupffer cells, cross-species binding of human SIRPa to pig CD47 has a significantly higher binding affinity than to human CD47, without producing an inhibitory tyrosine phosphorylation signal on SIRPa [71-73]. This genetic modification may be further complicated by competition of human SIRPa with endogenous pig SIRPa for binding to available pig CD47. SIRPa is not only expressed on liver ECs and Kupffer cells, but also on circulating macrophages. Therefore, circulating macrophages need a CD47 signal on ECs or other cells to prevent macrophage activation, which may result in increased inflammatory responses with the production of TNF- $a$ and other cytokines by the human/primate macrophages.

Tena et al. recently reported the birth of a human CD47-expressing pig (though the health and survival of the pig have not been reported) [74]. However, given that porcine livers have been shown to react towards human platelets and hRBCs, the desirable transgenesis in the pig might be the expression of both human CD47 and human SIRPa. As complicated as the cross-species SIRPa-CD47 signal is, further evidence of the role of CD47 renders this 
interaction more complicated. The expression of CD47 on a cell is associated with an inflammatory state and an increase in vasoconstriction [75]. Therefore, an increase in CD47 expression (e.g., by transgenic expression of human CD47 in the pig) may be harmful to the outcome of the graft. Of relevance to this complicated signal, CD47 may serve as a receptor for thrombospondin-1 [76], which limits the angiogenic and vasodilator activities of nitric oxide, plays a role in platelet aggregation by thrombin [77] and regulates $\mathrm{T}$ cell survival via CD47 [78].

\section{Cross-species thromboregulation}

The imbalance between human 'coagulation' factors and pig 'anticoagulation' factors, can be quantitative or qualitative. Almost all coagulation factors are produced by the liver, and hence cross-species thromboregulation becomes more complicated in case of liver xenotransplantation.

\section{Thrombomodulin}

Pig thrombomodulin is a poor activator of human thrombin, resulting in a low production of activated human protein C [79-82]. Several groups have recently reported the production of human thrombomodulin-expressing pigs [83-86]. Published evidence from in vitro [87] and transgenic mouse [88] models suggests that expression of human thrombomodulin will have salutary impacts on coagulation dysfunction and inflammation, both of which have been identified as problems in xenotransplantation.

Of relevance, the Pittsburgh group has recently performed a heart xenotransplantation in a baboon using a heart from a GTKO.hCD46.hThrombomodulin pig [83]. The recipient baboon maintained a stable platelet count and fibrinogen level throughout the experiment, indicating no or minimal activation of platelets, and no consumptive coagulopathy [ЕКевR в, unPUBLShED DatA]. Two other baboons received hearts from multi-transgenic pigs (GTKO.hCD55.hCD59.hCD39.hThrombomodulin) with similar outcome [ЕКSER в, UNPUBLLSHED DATA . Although this encouraging preliminary preclinical in vivo data offer hope for a solution to cross-species coagulation dysregulation, transgenic expression of human endothelial protein $\mathrm{C}$ receptor may also be required for maximal effect [89-91].

\section{TF pathway inhibitor}

TF expression, mainly on recipient platelets, recipient ECs and also possibly on donor liver or kidney ECs, appears to be detrimental to the survival of the xenograft [42,92]. Initial evidence suggested incompatibilities with porcine TF pathway inhibitor (TFPI) and human FXa [93]. Recent evidence by Lee et al., in an in vitro study using primate cell-generated recombinant TFPI, showed that there are no apparent incompatibilities between appropriately glycosylated recombinant pig TFPI and the human TF pathway [94]. Additional transgenic expression of human TFPI on the ECs of the pig may provide benefit, as TFPI is rapidly shed from the inflamed vasculature [95]. Hitherto, the only published report of a viable healthy pig expressing human TFPI is where human TFPI was expressed specifically in the pancreas, using an islet-specific expression system [96]. For liver and other organs, expression of human TFPI should possibly be restricted to the ECs of the vasculature, rather than ubiquitously, since high levels of human TFPI in the pig may not be compatible with the life of the pig [AYARES D, unPUB LISHed DATA].

\section{CD39/CD73}

Human CD39 (ecto-nucleoside triphosphate diphosphohydrolase) is responsible for breakdown of ATP to ADP and then to AMP. AMP is hydrolyzed by ecto- 5 '-nucleotidase (CD73) to adenosine, which is an antithrombotic and cardiovascular-protective mediator 
[97,98]. Dwyer et al. demonstrated that transgenic expression of human CD39 in a mouse model of cardiac allotransplantation was associated with impaired platelet aggregation, prolonged bleeding times and resistance to systemic thromboembolism. Donor hearts transgenic for human CD39 were substantially protected from thrombosis and survived longer $[99,100]$. Recent studies confirmed the protective effect of transgenic expression of human CD39 in a murine model of myocardial [101] and renal [102] ischemia/reperfusion injury. Wheeler et al. recently demonstrated the protective effect of human CD39 in a large animal model, using pigs transgenic for human CD39 expression [98].

Preclinical studies in a pig-to-nonhuman primate kidney xenotransplantation model, using pigs transgenic for GTKO. hCD55.hCD59.hCD39 did not show encouraging results, albeit in these studies the levels of expression of human CD39 on ECs in the transgenic pig line was suboptimal $[103,104]$.

\section{von Willebrand Factor}

As mentioned above, pig vWF activates recipient baboon platelets. Evidence suggests that pig vWF knockout and human vWF knockin will be required [57,67], since a vWF-knockout pig would have a tendency to bleed and would be unhealthy. Schulte Am Esch et al. demonstrated species functional incompatibility of porcine vWF for human platelet GPIb receptors [66]. Due to the large size of the vWF locus and complexity of this gene, the development of pigs that express human vWF will be difficult. Therefore, selective manipulation of individual GPIb binding sites on pig vWF may be required. The different levels of sialic acid expression by platelet vWF receptors increases concerns of relative desialylation levels, resulting in increased platelet clearance, especially in liver xenotransplantation.

\section{Expert commentary \& five-year view on clinical perspective}

Although the abovementioned efforts to prevent platelet activation and phagocytosis have been limited, the combination of several approaches could make a significant impact on pig liver xenotransplantation.

Having documented an absence of HAR and of early AHXR following the transplantation of a genetically engineered pig liver into a nonhuman primate [13,14,27,29], we believe that if the severe and immediate thrombocytopenia could be prevented, a clinical trial of pig liver xenotransplantation as a bridge to allotransplantation might be possible.

The increasingly rapid development of genetically engineered pigs will bring clinical xenotransplantation closer. More preclinical (pig-to-nonhuman primate) studies will be needed to demonstrate the unimpaired health of the organ-source pig, particularly the absence of any detrimental effect of over-expression of human genes on the coagulation pathways in the pig, and consistent extended survival of transplanted pig livers in nonhuman primates in the absence of life-threatening complications, before 'bridging' trials of pig liver xenotransplantation can begin in patients with ALF.

Although it is hard to estimate the exact number of genetic modifications that may be required in the organ-source pig for clinical liver xenotransplantation, we have recently discussed what genetic modifications may be necessary for clinical lung xenotransplantation [91]. As there are many similarities between lung and liver xenotransplantation, this review may act as a guide [91]. 


\section{Acknowledgments}

D Ayares is an employee of Revivicor Inc. B Ekser is a recipient of a NIH NIAID T32 AI 074490 Training Grant. Work on xenotransplantation in the Thomas E. Starzl Transplantation Institute of the University of Pittsburgh, PA, USA, is supported in part by NIH grant U19 AI090959-01, and by Sponsored Research Agreements between the University of Pittsburgh and Revivicor, Inc., Blacksburg, VA, USA. Work on xenotransplantation at the University of Toledo Health Science Campus, OH, USA, is supported by NIH grant, 5R01DK066160-05.

No writing assistance was utilized in the production of this manuscript.

\section{References}

Papers of special note have been highlighted as:

- of interest

•• of considerable interest

1. Nguyen NT, Vierling JM. Acute liver failure. Curr Opin Organ Transplant. 2011; 16(3):289-296. [PubMed: 21519261]

2. Ekser B, Gridelli B, Tector AJ, Cooper DK. Pig liver xenotransplantation as a bridge to allotransplantation: which patients might benefit? Transplantation. 2009; 88(9):1041-1049. [PubMed: 19898198]

3. Bernal W, Auzinger G, Dhawan A, Wendon J. Acute liver failure. Lancet. 2010; 376(9736):190201. [PubMed: 20638564]

4. Cooper DK, Gollackner B, Sachs DH. Will the pig solve the transplantation backlog? Annu Rev Med. 2002; 53:133-147. [PubMed: 11818467]

$5^{* *}$. Lexer G, Cooper DK, Rose AG, et al. Hyperacute rejection in a discordant (pig to baboon) cardiac xenograft model. J Heart Transplant. 1986; 5(6):411-418. First description of hyperacute rejection of an organ graft in the pig-to-nonhuman primate model. [PubMed: 3302173]

6. Ekser B, Cooper DK. Overcoming the barriers to xenotransplantation: prospects for the future. Expert Rev Clin Immunol. 2010; 6(2):219-230. [PubMed: 20402385]

7. Yang YG, Sykes M. Xenotransplantation: current status and a perspective on the future. Nat Rev Immunol. 2007; 7(7):519-531. [PubMed: 17571072]

8. Good AH, Cooper DK, Malcolm AJ, et al. Identification of carbohydrate structures that bind human antiporcine antibodies: implications for discordant xenografting in humans. Transplant Proc. 1992; 24(2):559-562. [PubMed: 1566430]

9. Galili U, Shohet SB, Kobrin E, Stults CL, Macher BA. Man, apes, and Old World monkeys differ from other mammals in the expression of a-galactosyl epitopes on nucleated cells. J Biol Chem. 1988; 263(33):17755-17762. [PubMed: 2460463]

10. Galili U. Interaction of the natural anti-Gal antibody with a-galactosyl epitopes: a major obstacle for xenotransplantation in humans. Immunol Today. 1993; 14(10):480-482. [PubMed: 7506033]

11. Bach FH, Winkler H, Ferran C, Hancock WW, Robson SC. Delayed xenograft rejection. Immunol Today. 1996; 17(8):379-384. [PubMed: 8783499]

12. Schuurman HJ, Cheng J, Lam T. Pathology of xenograft rejection: a commentary. Xenotransplantation. 2003; 10(4):293-299. [PubMed: 12795678]

13**. Ekser B, Long C, Echeverri GJ, et al. Impact of thrombocytopenia on survival of baboons with genetically modified pig liver transplants: clinical relevance. Am J Transplant. 2010; 10(2):273285. The largest experience of preclinical genetically engineered pig-to-nonhuman primate pig liver xenotransplantation. [PubMed: 20041862]

14. Schuetz C, Kim K, Elias N, et al. 9-day survival and control of thrombocytopenia following liver xenotransplantation in baboons using GalT-KO swine grafts. Xenotransplantation. 2012; 19(4): 256-264. [PubMed: 22909139]

15. Ezzelarab M, Hara H, Busch J, et al. Antibodies directed to pig non-Gal antigens in naïve and sensitized baboons. Xenotransplantation. 2006; 13(5):400-407. [PubMed: 16925663] 
16. Cooper DK. Xenoantigens and xenoantibodies. Xenotransplantation. 1998; 5(1):6-17. [PubMed: 9507728]

17. Chen G, Qian H, Starzl T, et al. Acute rejection is associated with antibodies to non-Gal antigens in baboons using Gal-knockout pig kidneys. Nat Med. 2005; 11(12):1295-1298. [PubMed: 16311604]

18. Byrne GW, Stalboerger PG, Davila E, et al. Proteomic identification of non-Gal antibody targets after pig-to-primate cardiac xenotransplantation. Xenotransplantation. 2008; 15(4):268-276. [PubMed: 18957049]

19. Byrne GW, Stalboerger PG, Du Z, Davis TR, McGregor CG. Identification of new carbohydrate and membrane protein antigens in cardiac xenotransplantation. Transplantation. 2011; 91(3):287292. [PubMed: 21119562]

20. Burlak C, Wang ZY, Chihara RK, et al. Identification of human preformed antibody targets in GTKO pigs. Xenotransplantation. 2012; 19(2):92-101. [PubMed: 22497511]

21. Ezzelarab M, Garcia B, Azimzadeh A, et al. The innate immune response and activation of coagulation in a1, 3-galactosyltransferase gene-knockout xenograft recipients. Transplantation. 2009; 87(6):805-812. [PubMed: 19300181]

22*. Makowa L, Cramer DV, Hoffman A, et al. The use of a pig liver xenograft for temporary support of a patient with fulminant hepatic failure. Transplantation. 1995; 59(12):1654-1659. The first report using a pig liver in an acute liver failure patient. [PubMed: 7604434]

23. Calne RY, White HJ, Herbertson BM, et al. Pig-to-baboon liver xenografts. Lancet. 1968; 1(7553): 1176-1178. [PubMed: 4172293]

24. Calne RY, Davis DR, Pena JR, et al. Hepatic allografts and xenografts in primates. Lancet. 1970; 1(7638):103-106. [PubMed: 4188721]

25. Powelson J, Cosimi AB, Austen W Jr, et al. Porcine-to-primate orthotopic liver transplantation. Transplant Proc. 1994; 26(3):1353-1354. [PubMed: 8029937]

26. Luo Y, Kosanke S, Mieles L, et al. Comparative histopathology of hepatic allografts and xenografts in the nonhuman primate. Xenotransplantation. 1998; 5(3):197-206. [PubMed: 9741458]

27*. Ramírez P, Chavez R, Majado M, et al. Life-supporting human complement regulator decay accelerating factor transgenic pig liver xenograft maintains the metabolic function and coagulation in the nonhuman primate for up to 8 days. Transplantation. 2000; 70(7):989-998. First report of transgenic pig liver transplant in a nonhuman primate. [PubMed: 11045632]

28*. Ekser B, Gridelli B, Veroux M, Cooper DK. Clinical pig liver xenotransplantation: how far do we have to go? Xenotransplantation. 2011; 18(3):158-167. Review on the current status of pig liver xenotransplantation. [PubMed: 21696445]

29*. Ekser B, Klein E, He J, et al. Geneticallyengineered pig-to-baboon liver xenotransplantation: histopathology of xenografts and native organs. PLoS ONE. 2012; 7(1):e29720. Report on detailed histopathology of pig liver xenografts and native organs of recipients. [PubMed: 22247784]

30. Ramírez P, Montoya MJ, Ríos A, et al. Prevention of hyperacute rejection in a model of orthotopic liver xenotransplantation from pig to baboon using polytransgenic pig livers (CD55, CD59, and Htransferase). Transplant Proc. 2005; 37(9):4103-4106. [PubMed: 16386637]

31. Phelps CJ, Koike C, Vaught TD, et al. Production of a1,3-galactosyltransferasedeficient pigs. Science. 2003; 299(5605):411-414. [PubMed: 12493821]

32. Yamada K, Yazawa K, Shimizu A, et al. Marked prolongation of porcine renal xenograft survival in baboons through the use of a1,3-galactosyltransferase gene-knockout donors and the cotransplantation of vascularized thymic tissue. Nat Med. 2005; 11(1):32-34. [PubMed: 15619627]

33. Kuwaki K, Tseng YL, Dor FJ, et al. Heart transplantation in baboons using a1,3galactosyltransferase gene-knockout pigs as donors: initial experience. Nat Med. 2005; 11(1):29_ 31. [PubMed: 15619628]

34. Tseng YL, Kuwaki K, Dor FJ, et al. a1,3-Galactosyltransferase gene-knockout pig heart transplantation in baboons with survival approaching 6 months. Transplantation. 2005; 80(10): 1493-1500. [PubMed: 16340796] 
35. Robson SC, Cooper DK, d'Apice AJ. Disordered regulation of coagulation and platelet activation in xenotransplantation. Xenotransplantation. 2000; 7(3):166-176. [PubMed: 11021661]

36. Shimizu A, Hisashi Y, Kuwaki K, et al. Thrombotic microangiopathy associated with humoral rejection of cardiac xenografts from a1,3-galactosyltransferase gene-knockout pigs in baboons. Am J Pathol. 2008; 172(6):1471-1481. [PubMed: 18467706]

37. Ekser B, Echeverri GJ, Hassett AC, et al. Hepatic function after genetically engineered pig liver transplantation in baboons. Transplantation. 2010; 90(5):483-493. [PubMed: 20606605]

38. Tector AJ, Berho M, Fridell JA, et al. Rejection of pig liver xenografts in patients with liver failure: implications for xenotransplantation. Liver Transpl. 2001; 7(2):82-89. [PubMed: 11172389]

39. Tector AJ, Fridell JA, Elias N, et al. Aberrations in hemostasis and coagulation in untreated discordant hepatic xenotransplantation: studies in the dog-to-pig model. Liver Transpl. 2002; 8(2): 153-159. [PubMed: 11862592]

40. Kirk AD, Morrell CN, Baldwin WM 3rd. Platelets influence vascularized organ transplants from start to finish. Am J Transplant. 2009; 9(1):14-22. [PubMed: 19067663]

41*. Ezzelarab M, Ekser B, Gridelli B, Iwase H, Ayares D, Cooper DK. Thrombocytopenia after pigto-baboon liver xenotransplantation: where do platelets go? Xenotransplantation. 2011; 18(6): 320-327. Report of an in vivo assessment of platelets and their interactions with leukocytes and their subsets. [PubMed: 22168139]

42*. Ekser B, Lin CC, Long C, et al. Potential factors influencing the development of thrombocytopenia and consumptive coagulopathy after genetically-modified pig liver xenotransplantation. Transplant Int. 2012; 25(8):882-896. Identification of potential factors, including the involvement of platelet and endothelial cell microparticles, in the development of thrombocytopenia after pig liver xenotransplantation.

43**. Burlak C, Paris LL, Chihara RK, et al. The fate of human platelets perfused through the pig liver: implications for xenotransplantation. Xenotransplantation. 2010; 175:350-361. The first manuscript reporting evidence of platelet phagocytosis by pig liver sinusoidal endothelial cells and hepatocytes. [PubMed: 20955292]

44. Rees MA, Butler AJ, Davies HF, et al. Porcine livers perfused with human blood mount a graftversus-“host" reaction. Transplantation. 2002; 73(9):1460-1467. [PubMed: 12023625]

45. Rees MA, Butler AJ, Chavez-Cartaya G, et al. Prolonged function of extracorporeal hDAF transgenic pig livers perfused with human blood. Transplantation. 2002; 73(8):1194-1202. [PubMed: 11981409]

46*. Rees MA, Butler AJ, Negus MC, Davies HF, Friend PJ. Classical pathway complement destruction is not responsible for the loss of human erythrocytes during porcine liver perfusion. Transplantation. 2004; 77(9):1416-1423. Report of phagocytosis of human erythrocytes by a porcine liver. [PubMed: 15167601]

47. Burdorf L, Barth RN, Zhang T, et al. Pilot evaluation of anti-GPIb effects on platelet sequestration in an ex vivo xenogeneic pig liver perfusion model. Transplantation. 2010; 90(Suppl. 327) Abstract TTS 3132.

48*. Paris LL, Chihara RK, Sidner RA, Tector AJ, Burlak C. Differences in human and porcine platelet oligosaccharides may influence phagocytosis by liver sinusoidal cells in vitro. Xenotransplantation. 2012; 19(1):31-39. Report of in vitro experiments with human and porcine platelets and their impact in phagocytosis by liver sinusoidal endothelial cells. [PubMed: 22360751]

49*. Paris LL, Chihara RK, Reyes LM, et al. ASGR1 expressed by porcine enriched liver sinusoidal endothelial cells mediates human platelet phagocytosis in vitro. Xenotransplantation. 2011; 18(4):245-251. Identification of a receptor on the porcine liver sinusoidal endothelial cells that mediates human platelet phagocytosis. [PubMed: 21848542]

50*. Chihara RK, Paris LL, Reyes LM, et al. Primary porcine Kupffer cell phagocytosis of human platelets involves the CD18 receptor. Transplantation. 2011; 92(7):739-744. Identification of a Kupffer cell receptor that is involved in xenogeneic platelet phagocytosis. [PubMed: 21836538]

51. Peng QBL, Yeh H, Enjoji K, et al. Integrin-dependent baboon platelet activation and phagocytosis by porcine hepatocytes and endothelial cells. Xenotransplantation. 2011; 18:287. 
52. Gainetdinov RR, Premont RT, Bohn LM, Lefkowitz RJ, Caron MG. Desensitization of G proteincoupled receptors and neuronal functions. Annu Rev Neurosci. 2004; 27:107-144. [PubMed: 15217328]

53. Munro JM, Pober JS, Cotran RS. Tumor necrosis factor and interferon- $\gamma$ induce distinct patterns of endothelial activation and associated leukocyte accumulation in skin of Papio anubis. Am J Pathol. 1989; 135(1):121-133. [PubMed: 2505619]

54. Bach FH, Robson SC, Ferran C, et al. Endothelial cell activation and thromboregulation during xenograft rejection. Immunol Rev. 1994; 141:5-30. [PubMed: 7868157]

55. Schulte am Esch J 2nd, Cruz MA, Siegel JB, Anrather J, Robson SC. Activation of human platelets by the membrane-expressed A1 domain of von Willebrand factor. Blood. 1997; 90:4425-4437. [PubMed: 9373253]

56. Schulte am Esch J 2nd, Robson SC, Knoefel WT, Eisenberger CF, Peiper M, Rogiers X. Impact of $O$-linked glycosylation of the VWF-A1-domain flanking regions on platelet interaction. $\mathrm{Br} \mathrm{J}$ Haematol. 2005; 128:82-90. [PubMed: 15606553]

57. Cantu E, Balsara KR, Li B, et al. Prolonged function of macrophage, von Willebrand factordeficient porcine pulmonary xenografts. Am J Transplant. 2007; 7(1):66-75. [PubMed: 17109734]

58. Pascher Sauer IM, Hammer C, Gerlach JC, Neuhaus P. Extracorporeal liver perfusion as hepatic assist in acute liver failure: a review of world experience. Xenotransplantation. 2002; 9:309-324. [PubMed: 12199863]

59. Rees MA, Butler AJ, Brons IG, Negus MC, Skepper JN, Friend PJ. Evidence of macrophage receptors capable of direct recognition of xenogeneic epitopes without opsonization. Xenotransplantation. 2005; 12(1):13-19. [PubMed: 15598269]

60. Rees MA. A novel role for lectins in xenotransplantation. Xenotransplantation. 2005; 12:7-12. [PubMed: 15598268]

61. Burlak C, Twining LM, Rees MA. Terminal sialic acid residues on human glycophorin A are recognized by porcine kupffer cells. Transplantation. 2005; 80(3):344-352. [PubMed: 16082330]

62**. Brock LG, Delputte PL, Waldman JP, Nauwynck HJ, Rees MA. Porcine sialoadhesin: a newly identified xenogeneic innate immune receptor. Am J Transplant. 2012 (Epub ahead of print). Identification of a new xenogeneic innate immune receptor. 10.1111/j.1600-6143.2012.04247.x

63. Waldman JP, Vogel T, Friend P, Rees MA. Blocking porcine sialoadhesin improves extracorporeal porcine liver xenoperfusion. Xenotransplantation. 2011; 18 abstract \#130.

64. Hara H, Gridelli B, Lin YJ, Marcos A, Cooper DK. Liver xenografts for the treatment of acute liver failure: clinical and experimental experience and remaining immunologic barriers. Liver Transpl. 2008; 14(4):425-434. [PubMed: 18383106]

65. Hara H, Campanile N, Tai HC, et al. An in vitro model of pig liver xenotransplantation-pig complement is associated with reduced lysis of wild-type and genetically modified pig cells. Xenotransplantation. 2010; 17(5):370-378. [PubMed: 20955293]

66. Schulte am Esch J 2nd, Robson SC, Knoefel WT, Hosch SB, Rogiers X. $O$-linked glycosylation and functional incompatibility of porcine von Willebrand factor for human platelet GPIb receptors. Xenotransplantation. 2005; 12:30-37. [PubMed: 15598271]

67. Rumjantseva V, Grewal PK, Wandall HH, et al. Dual roles for hepatic lectin receptors in the clearance of chilled platelets. Nat Med. 2009; 15(11):1273-1280. [PubMed: 19783995]

68*. Ekser B, Ezzelarab M, Hara H, et al. Clinical xenotransplantation: the next medical revolution? Lancet. 2012; 379(9816):672-683. Review on the current status of xenotransplantation of cells, tissues and organs. [PubMed: 22019026]

69. Takenaka K, Prasolava TK, Wang JC, et al. Polymorphism in Sirpa modulates engraftment of human hematopoietic stem cells. Nat Immunol. 2007; 8(12):1313-1323. [PubMed: 17982459]

70. Paris LL, Reyes LM, Tector AJ. SIRPa interspecies incompatibilities lead to xenogeneic phagocytosis of platelets by liver cells. Xenotransplantation. 2011; 18 abstract \#411.

71. Ide K, Wang H, Tahara H, et al. Role for CD47-SIRP-a signaling in xenograft rejection by macrophages. Proc Natl Acad Sci USA. 2007; 104(12):5062-5066. [PubMed: 17360380]

72. Yang YG. CD47 in xenograft rejection and tolerance induction. Xenotransplantation. 2010; 17(4): 267-273. [PubMed: 20723199] 
73. Subramanian S, Tsai R, Discher DE. The 'metabolon,' CD47, and the 'phagocytic synapse': molecular co-localization and species divergence. Transfus Clin Biol. 2006; 13(1-2):31-38. [PubMed: 16581280]

74. Tena A, Vallabhajosyula P, Hawley RJ, Griesemer A, Yamada K, Sachs DH. Quantification of baboon thymopoiesis in porcine thymokidney xenografts by the signal-joining T-cell receptor excision circle assay. Transplantation. 2011; 91(6):639-644. [PubMed: 21285918]

75. Isenberg JS, Romeo MJ, Abu-Asab M, et al. Increasing survival of ischemic tissue by targeting CD47. Circ Res. 2007; 100(5):712-720. [PubMed: 17293482]

76. Isenberg JS, Ridnour LA, Dimitry J, Frazier WA, Wink DA, Roberts DD. CD47 is necessary for inhibition of nitric oxide-stimulated vascular cell responses by thrombospondin-1. J Biol Chem. 2006; 281(36):26069-26080. [PubMed: 16835222]

77. Isenberg JS, Romeo MJ, Yu C, et al. Thrombospondin-1 stimulates platelet aggregation by blocking the antithrombotic activity of nitric oxide/cGMP signaling. Blood. 2008; 111(2):613623. [PubMed: 17890448]

78. Lamy L, Foussat A, Brown EJ, Bornstein P, Ticchioni M, Bernard A. Interactions between CD47 and thrombospondin reduce inflammation. J Immunol. 2007; 178(9):5930-5939. [PubMed: 17442977]

79. Esmon CT, Owen WG. The discovery of thrombomodulin. J Thromb Haemost. 2004; 2(2):209213. [PubMed: 14995979]

80. Roussel JC, Moran CJ, Salvaris EJ, Nandurkar HH, d'Apice AJ, Cowan PJ. Pig thrombomodulin binds human thrombin but is a poor cofactor for activation of human protein C and TAFI. Am J Transplant. 2008; 8(6):1101-1112. [PubMed: 18444940]

81. Siegel JB, Grey ST, Lesnikoski BA, et al. Xenogeneic endothelial cells activate human prothrombin. Transplantation. 1997; 64(6):888-896. [PubMed: 9326416]

82. Kopp CW, Grey ST, Siegel JB, et al. Expression of human thrombomodulin cofactor activity in porcine endothelial cells. Transplantation. 1998; 66(2):244-251. [PubMed: 9701273]

83. Ayares D, Phelps C, Vaught T, et al. Multi-transgenic pigs for vascularized pig organ xenografts. Xenotransplantation. 2011; 18 abstract 119.

84. Iwamoto M, Yazaki S, Onishi A, et al. Successful production and breeding of cloned pigs expressing human thrombomodulin in endothelial cells. Xenotransplantation. 2011; 18 Abstract 125.

85. Klymiuk N, Wuensch A, Kurome M, et al. GalT-KO/CD46/hTM triple-transgenic donor animals for pig-to-baboon heart transplantation. Xenotransplantation. 2011; 18 abstract \#126.

86. Salvaris E, Fisicaro N, Harrison S, et al. Expression of human thrombomodulin in GTKO/hCD55CD59-HTF pigs. Xenotransplantation. 2011; 18 abstract \#513.

87. Miwa Y, Yamamoto K, Onishi A, et al. Potential value of human thrombomodulin and DAF expression for coagulation control in pig-to-human xenotransplantation. Xenotransplantation. 2010; 17(1):26-37. [PubMed: 20149186]

88. Crikis S, Zhang XM, Dezfouli S, et al. Anti-inflammatory and anticoagulant effects of transgenic expression of human thrombomodulin in mice. Am J Transplant. 2010; 10(2):242-250. [PubMed: 20055798]

89. d'Apice AJ, Cowan PJ. Xenotransplantation: the next generation of engineered animals. Transpl Immunol. 2009; 21(2):111-115. [PubMed: 18973810]

90. Esmon CT. The endothelial protein C receptor. Curr Opin Hematol. 2006; 13(5):382-385. [PubMed: 16888445]

91*. Cooper DK, Ekser B, Burlak C, et al. Clinical lung xenotransplantation-what donor genetic modifications may be necessary? Xenotransplantation. 2012; 19(3):144-158. Review of genetic modification that might be beneficial to the organ source pig. [PubMed: 22702466]

92. Lin CC, Ezzelarab M, Shapiro R, et al. Recipient tissue factor expression is associated with consumptive coagulopathy in pig-to-primate kidney xenotransplantation. Am J Transplant. 2010; 10(7):1556-1568. [PubMed: 20642682]

93. Kopp CW, Siegel JB, Hancock WW, et al. Effect of porcine endothelial tissue factor pathway inhibitor on human coagulation factors. Transplantation. 1997; 63(5):749-758. [PubMed: 9075849] 
94. Lee KF, Salvaris EJ, Roussel JC, Robson SC, d'Apice AJ, Cowan PJ. Recombinant pig TFPI effciently regulates human tissue factor pathways. Xenotransplantation. 2008; 15(3):191-197. [PubMed: 18611227]

95. Chen D, Giannopoulos K, Shiels PG, et al. Inhibition of intravascular thrombosis in murine endotoxemia by targeted expression of hirudin and tissue factor pathway inhibitor analogs to activated endothelium. Blood. 2004; 104(5):1344-1349. [PubMed: 15126322]

96. Phelps C, Vaught T, Ball S, et al. Multi-transgenic pigs designed for xenoislet transplants. Xenotransplantation. 2009; 16 Abstract-IXA-O-7.3.

97. Kaczmarek E, Koziak K, Sévigny J, et al. Identification and characterization of CD39/vascular ATP diphosphohydrolase. J Biol Chem. 1996; 271(51):33116-33122. [PubMed: 8955160]

98. Wheeler DG, Joseph ME, Mahamud SD, et al. Transgenic swine: expression of human CD39 protects against myocardial injury. J Mol Cell Cardiol. 2012; 52(5):958-961. [PubMed: 22269791]

99. Dwyer KM, Robson SC, Nandurkar HH, et al. Thromboregulatory manifestations in human CD39 transgenic mice and the implications for thrombotic disease and transplantation. J Clin Invest. 2004; 113(10):1440-1446. [PubMed: 15146241]

100. Dwyer KM, Mysore TB, Crikis S, et al. The transgenic expression of human CD39 on murine islets inhibits clotting of human blood. Transplantation. 2006; 82(3):428-432. [PubMed: 16906044]

101. Köhler D, Eckle T, Faigle M, et al. CD39/ectonucleoside triphosphate diphosphohydrolase 1 provides myocardial protection during cardiac ischemia/reperfusion injury. Circulation. 2007; 116(16):1784-1794. [PubMed: 17909107]

102. Crikis S, Lu B, Murray-Segal LM, et al. Transgenic overexpression of CD39 protects against renal ischemia-reperfusion and transplant vascular injury. Am J Transplant. 2010; 10(12):25862595. [PubMed: 20840479]

103. Le Bas-Bernardet S, Branchereau J, Tillou X, et al. Porcine galactosyltransferase knock-out transgenic for human CD55, CD59, CD39 kidneys are actually rejected by baboons despite plasma/B cells and complement blockade. Xenotransplantation. 2011; 18 abstract \#556.

104. Le Bas-Bernardet S, Poirier N, Tillou X, et al. Preformed non-Gal antibodies are highly cytotoxic even against Galactosyltransferase knockout, human CD55, CD59, CD39 transgenic pig organs in a model of kidney transplantation into baboons. Xenotransplantation. 2011; 43(9):3426-3430.

105. Schneider MK, Ghielmetti M, Rhyner DM, Antsiferova MA, Seebach JD. Human leukocyte transmigration across Gala(1,3) Gal-negative porcine endothelium is regulated by human CD18 and CD99. Transplantation. 2009; 87(4):491-499. [PubMed: 19307784]

106. Puga Yung G, Schneider MK, Seebach JD. Immune responses to a-1,3 galactosyltransferase knockout pigs. Curr Opin Organ Transplant. 2009; 14(2):154-160. [PubMed: 19300259]

107. Holgersson J, Gustafsson A, Breimer ME. Characteristics of protein-carbohydrate interactions as a basis for developing novel carbohydrate-based antirejection therapies. Immunol Cell Biol. 2005; 83(6):694-708. [PubMed: 16266322]

\section{Website}

201. United Network for Organ Sharing (UNOS). [Accessed 15 April 2012] www.unos.org 


\section{Key issues}

- After pig liver xenotransplantation, the key current problem is platelet activation, aggregation and/or phagocytosis that cause immediate and severe thrombocytopenia, resulting in hemorrhage.

- There is an evidence of platelet phagocytosis by pig liver sinusoidal endothelial cells, hepatocytes and Kupffer cells.

- Platelets aggregate to each other, bind to white blood cells in the blood, sequestrated in the liver xenograft and removed from circulation in the native lungs.

- There is an evidence of initial tissue factor expression on platelets and peripheral blood mononuclear cells, which causes platelet aggregation without the need for liver sinusoidal endothelial cells activation.

- Genetically engineered a1,3-galactosyltransferase gene-knockout pigs have brought liver xenotransplantation a step closer to the clinic, with no hyperacute rejection or early acute humoral xenograft rejection, and normal or near-normal liver function and coagulation in the recipient nonhuman primate after xenotransplantation.

- Further genetic modifications may be well required to avoid platelet activation and phagocytosis, such as expression of thromboregulatory genes (CD39, thrombomodulin, endothelial protein $\mathrm{C}$ receptor) or knockdown of specific proaggregatory elements (e.g., asialoglycoprotein receptor-1, CD18) or expression of a specific protein (e.g., human signal regulatory protein- $\boldsymbol{\alpha}$ ).

- If immediate platelet activation and severe thrombocytopenia can be prevented, a clinical trial of genetically engineered pig liver xenotransplantation as a 'bridge' to allotransplantation in patients with acute liver failure may be justified.

- The expense of developing genetically engineered pigs is considerable, as is testing their organs in nonhuman primate models, and therefore this is a limiting factor in advancing the field. 


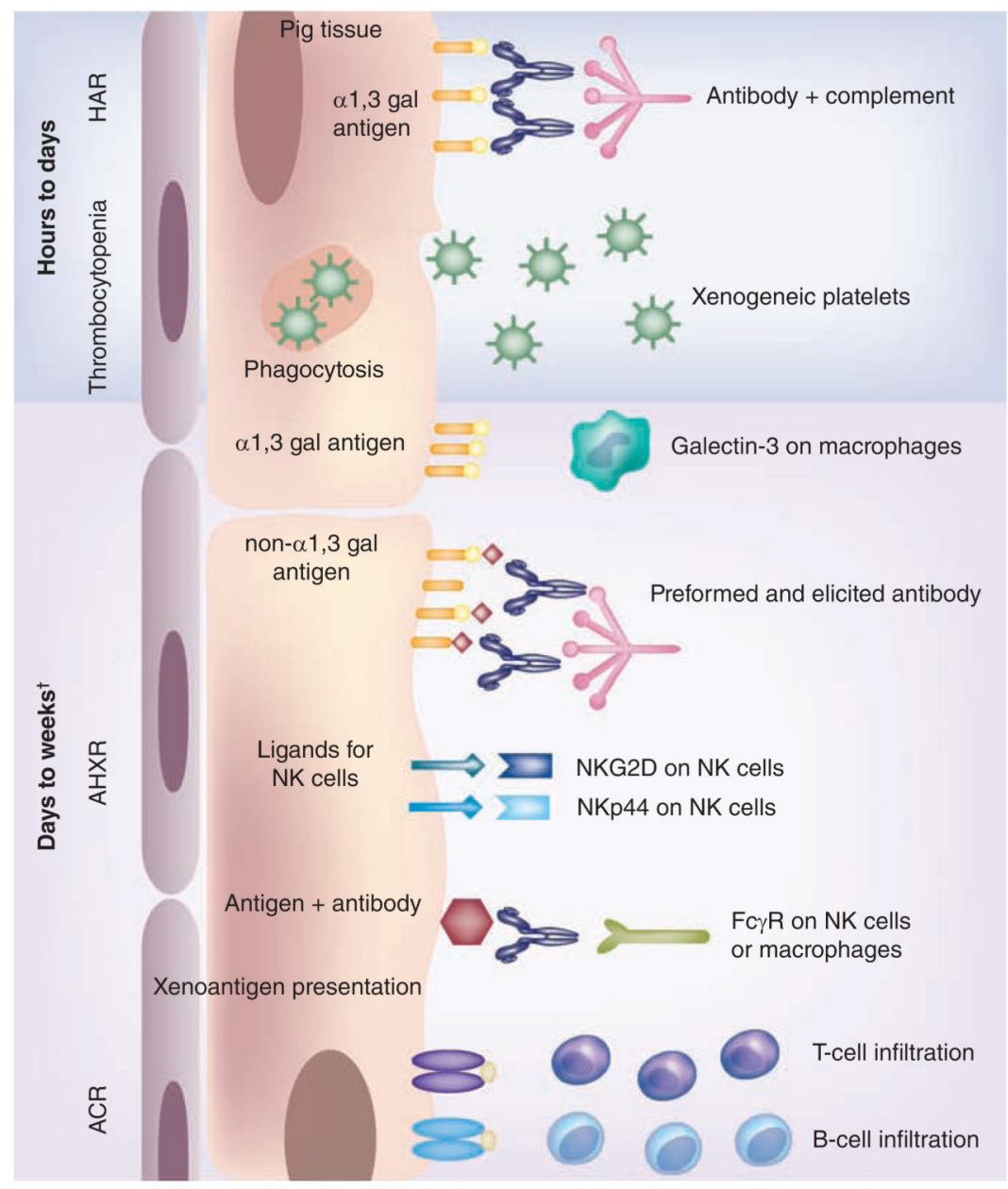

Figure 1. Immunological barriers to organ xenotransplantation

${ }^{\dagger}$ Events that are not clearly established or have not yet been observed in liver xenotransplantation.

ACR: Acute cellular rejection; AHXR: Acute humoral xenograft rejection; FcүR: Fc receptor for IgG; HAR: Hyperacute rejection; NK: Natural killer; NKG2D: Natural killer group 2 member D; NKp44: Natural killer p44.

For further information on immunological interactions, [105-107]. 


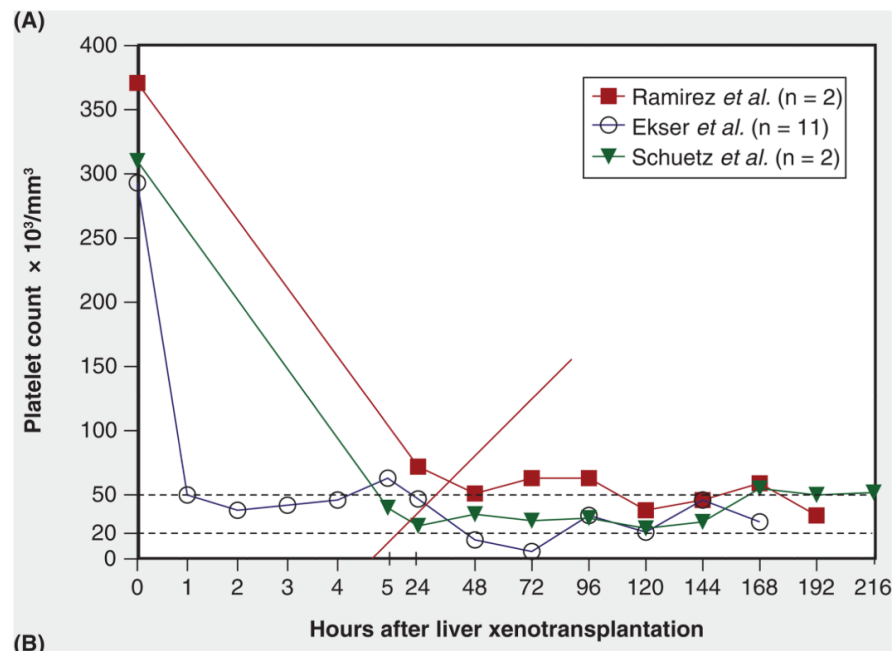

(B)

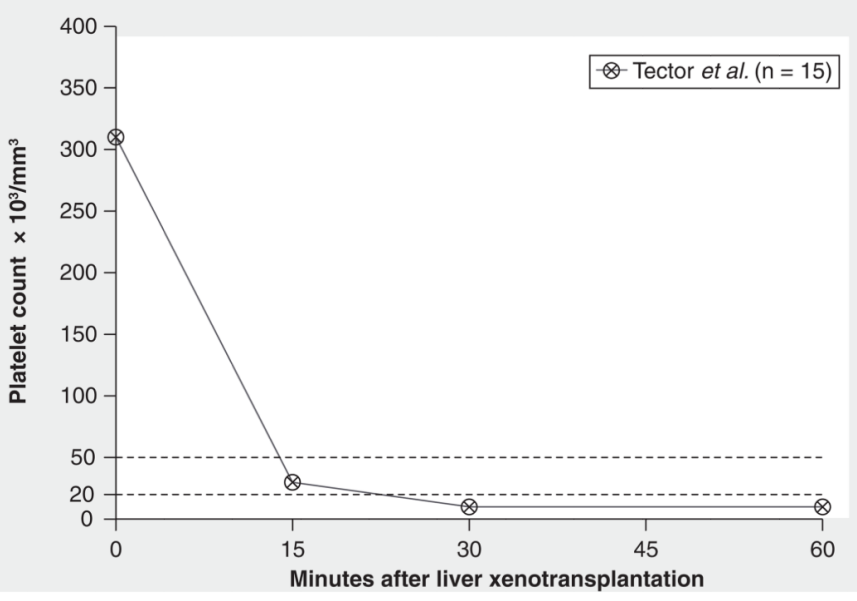

Figure 2. Platelet counts after in vivo orthotopic liver xenotransplantation

(A) Platelet counts after pig-to-baboon liver xenotransplantation: Ramírez et al. [27]; average of two WT.hCD55 pig liver xenotransplantations. Ekser et al. [13]; average of WT $(\mathrm{n}=1)$, GTKO $(\mathrm{n}=2)$, and GTKO.hCD46 $(\mathrm{n}=8)$ pig liver xenotransplantations. Schuetz et al. [14]; average of two GTKO pig liver xenotransplantations (estimated from Schuetz et al.). (B) Platelet counts after dog-to-pig liver xenotransplantation: Tector et al. [39]; average of 15 dog-to-pig liver xenotransplantations.

GTKO: a1,3-galactosyltransferase gene-knockout; WT: Wild-type. 

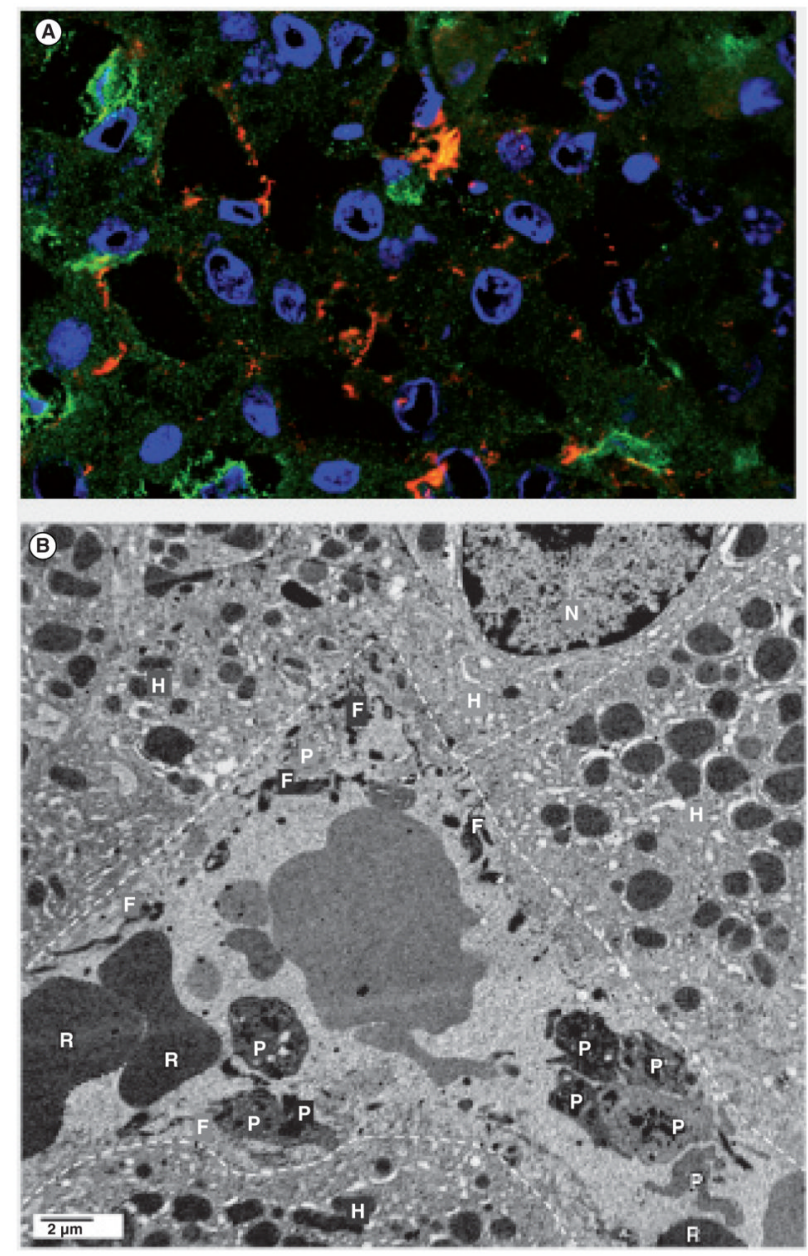

Figure 3. Platelet aggregation in liver sinusoidal endothelial cells

(A) Confocal microscopy of a GTKO/CD46 pig liver (in B7808) at necropsy (day 6) after immunofluorescence staining for platelets (CD41; red), PBMCs (CD45; green) and nuclei (DAPI; blue) showing platelet and platelet-PBMC aggregates in the liver sinusoids $(\times 1000)$. (Reproduced with permission from [13]). (B) Electron micrograph of pig liver xenograft $2 \mathrm{~h}$ after transplantation. Aggregation of platelets with fibrin deposition along the sinusoidal endothelial cells. The appearance of hepatocytes was normal. Dashed white lines indicate endothelial cells lining the sinusoids. (Solid black bar indicates $2 \mu \mathrm{m}$ ).

F: Fibrin; H: Hepatocyte; N: Nucleus; P: Platelet; R: Red blood cell. Reproduced with permission from [42]. 

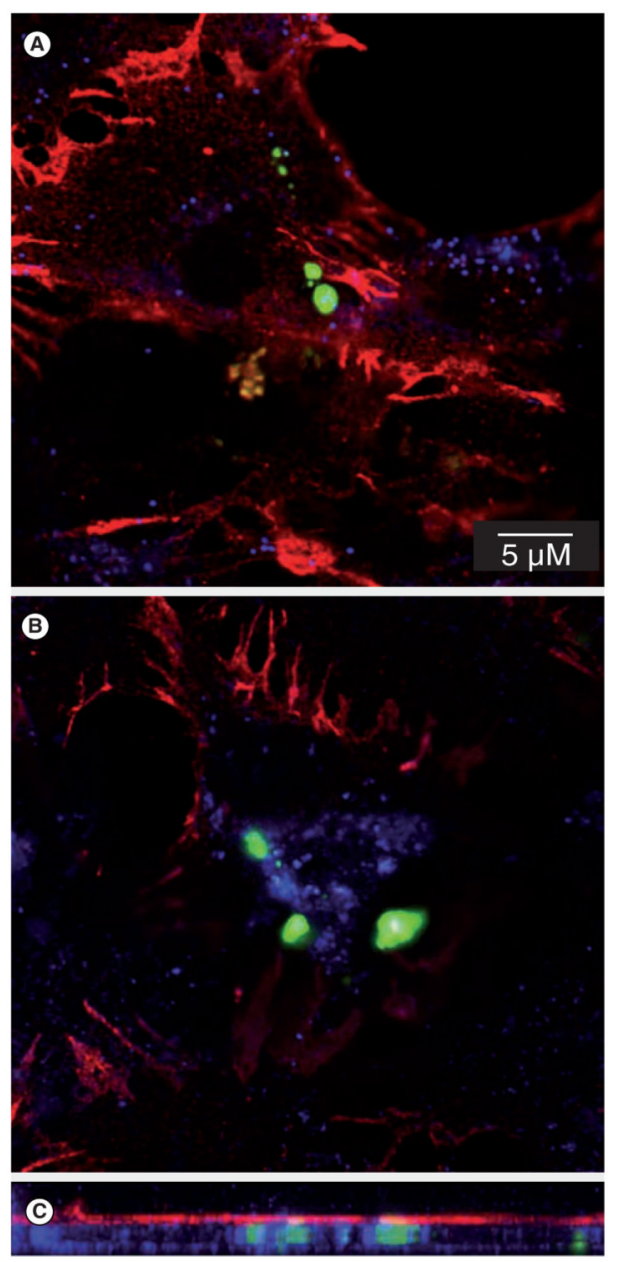

Figure 4. Platelet phagocytosis by liver cells

(A) Confocal microscope analysis of liver sinusoidal endothelial cells in vitro. Crystal field stabilisation energies-labeled human platelets (green) are phagocytosed by pig LSEC in primary culture in vitro. Primary LSEC are CD31-positive (red) and contain Weibel-Palade bodies as indicated by von Willebrand factor labeling (blue). (B) Human platelets contained phagosomes (green) colocalize with CD107a-positive lysosomes (blue) inside CD31positive LSEC (red). (C) Crystal field stabilisation energies-labeled human platelets (green) and CD107a-positive lysosomes (blue) colocalize beneath the endothelial cell surface (red) as detected by a Z-series analysis of the cells in panel B (C).

Reproduced with permission from [43]. 


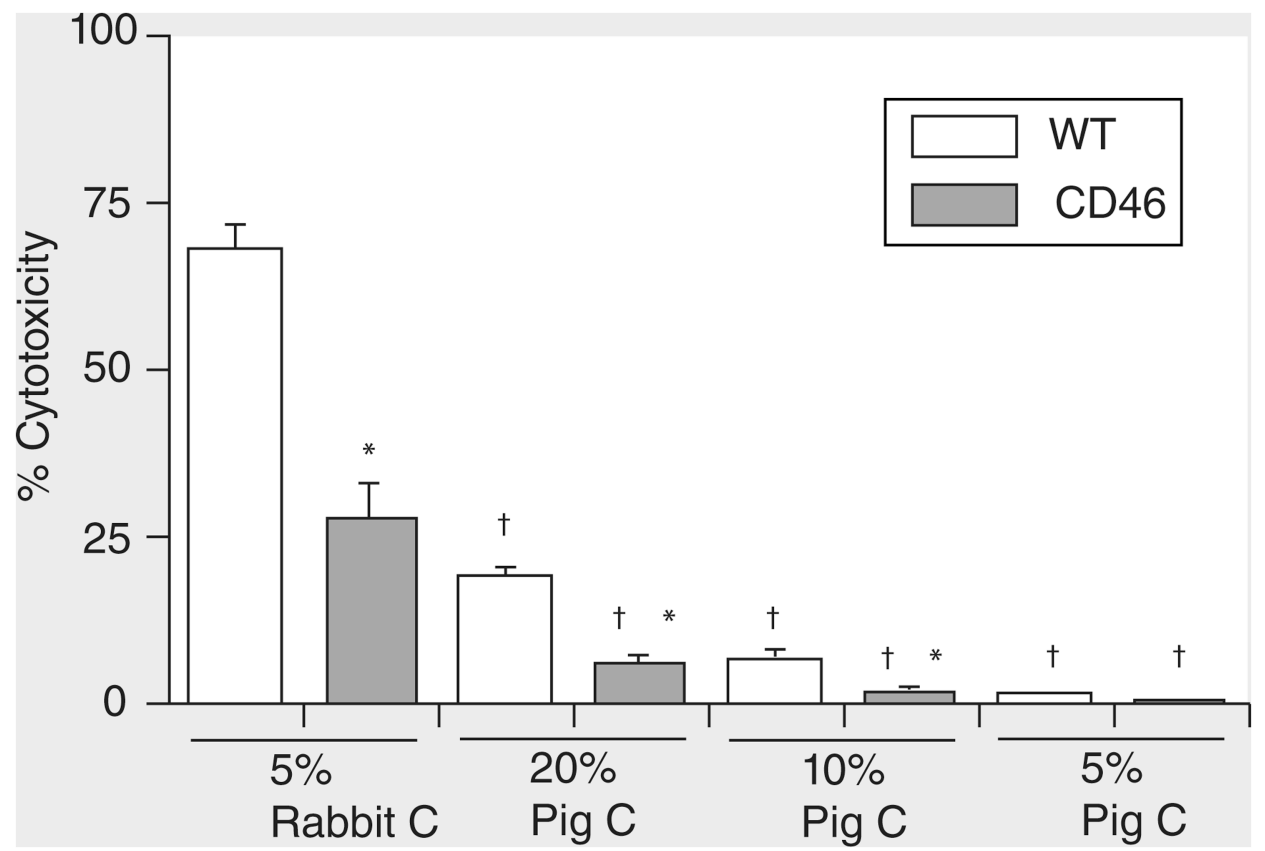

Figure 5. Protection of pig cells by expression of human CD46 in in vitro cytotoxicity assay The expression of CD46 on pig peripheral blood mononuclear cells (PBMCs) reduces lysis by heat-inactivated pooled human sera with added rabbit or WT pig C. WT (white bars) and CD46 (gray bars) pig PBMC were exposed to pooled heat-inactivated human serum $(12.5 \%)$ with added rabbit $\mathrm{C}(5 \%)$ or WT pig $\mathrm{C}$ (at 20, 10 and $5 \%)(\mathrm{n}=4)$. Expression of human CD46 on pig PBMC was associated with reduced lysis by human serum with either added rabbit $\mathrm{C}$ or added WT pig $\mathrm{C}$.

*Comparisons between WT and CD46 pig PBMC ( $<<0.01)$.

$\dagger$ Indicates comparisons between rabbit $\mathrm{C}$ and pig $\mathrm{C}$. Pig $\mathrm{C}$ was less cytotoxic than rabbit (or human) $\mathrm{C}$.

C: Complement; WT: Wild-type.

Reproduced with permission from [65]. 


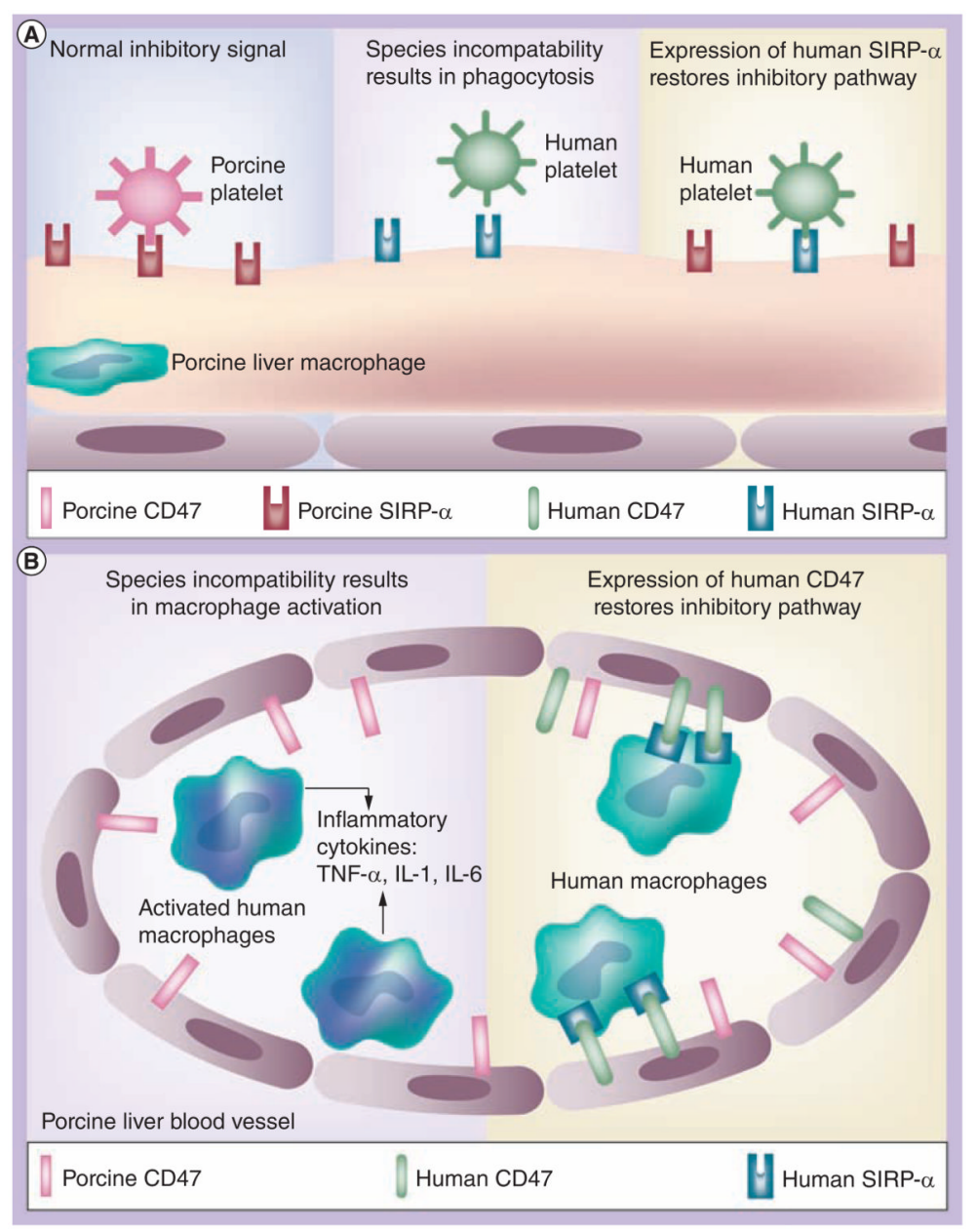

Figure 6. SIRPa-CD47 cross-species incompatibility

(A) Schematic representation of CD47-SIRPa interaction in relation to natural expression of SIRPa on pig Kupffer cells (liver macrophages). Left: in the organ-source pig, there is a normal inhibitory signal of porcine CD47 (in this example expressed on platelets) that is recognized by porcine SIRPa. Center: after pig liver xenotransplantation, there might be a lack of recognition of human CD47 by porcine SIRPa, resulting in phagocytosis of human platelets. Right: transgenic expression of human SIRPa on pig Kupffer cells would result in recognition of human CD47 on human platelets, thus inhibiting phagocytosis. (B) Left: after transplantation of an unmodified pig liver into a human, the expression of pig CD47 on the endothelial cells of the liver blood vessels will not be recognized by human SIRPaexpressing macrophages, which will therefore not be inhibited but will become activated; inflammatory cytokines will be produced and graft injury will occur. Right: when a liver from a pig transgenic for human CD47 is transplanted, the human SIRPa-expressing macrophages will recognize the pig tissues as 'self', and activation will be inhibited; cytokine production and graft injury will not occur.

Reproduced with permission from [91]. 

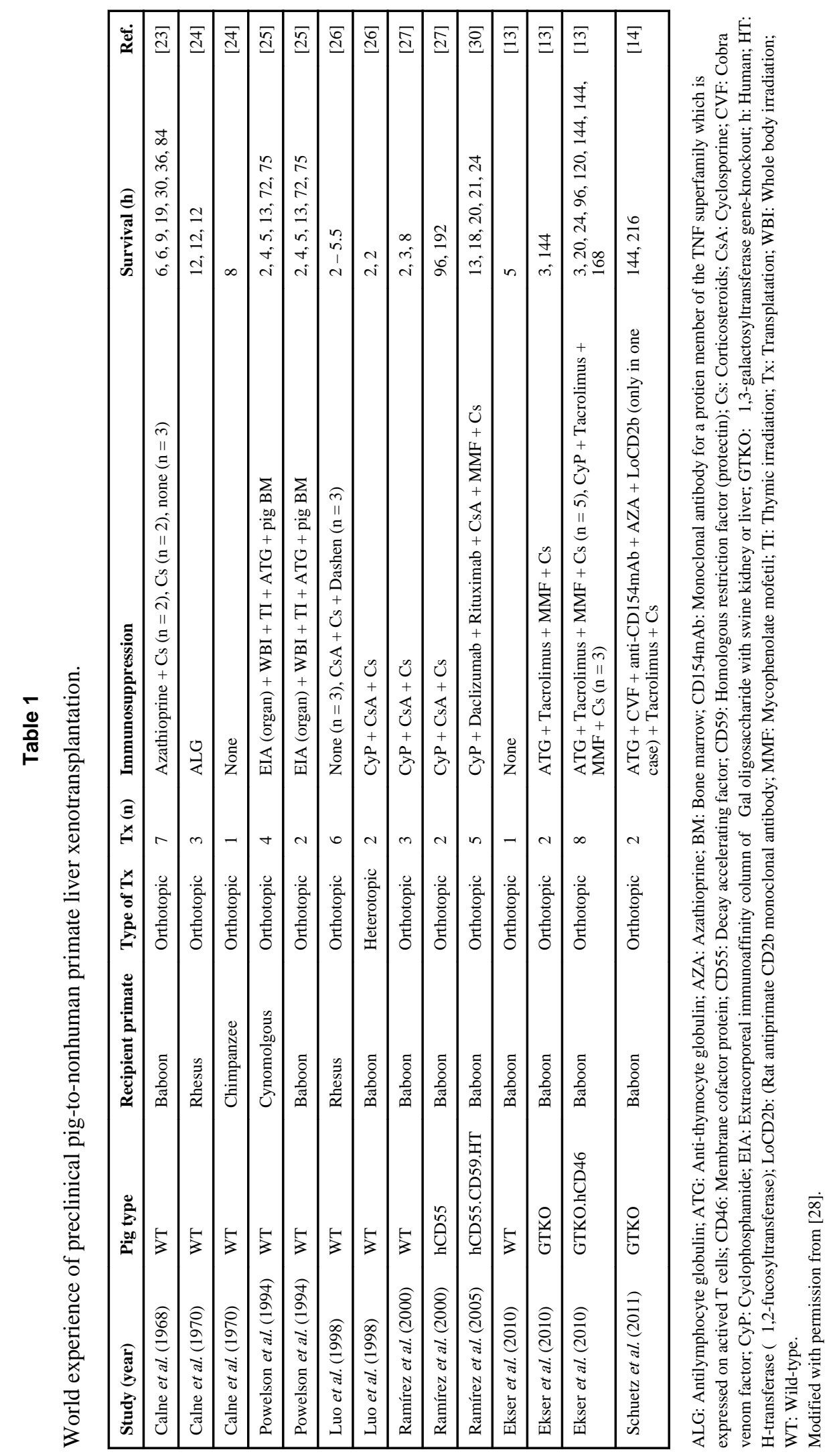

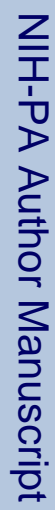

Expert Rev Clin Immunol. Author manuscript; available in PMC 2013 September 16. 